\title{
Friedel-Crafts benzylation of arenes with benzylic alcohols using sulfonic-acid-functionalized hyper-cross-linked poly(2-naphthol) as a solid acid catalyst
}

\author{
Reddi Mohan Naidu Kalla ${ }^{1}$, Raju Chakali ${ }^{2}$, Munikrishnaiah Amudala ${ }^{3}$, \\ Mavallur Varalakshmi ${ }^{\oplus}{ }^{4}$ and Chamarthi Naga Raju ${ }^{5}$ \\ ${ }^{1}$ Department of Science and Humanities, Sri Venkateswara Engineering College, Karakambadi Road, \\ Tirupati, Andhra Pradesh 517507, India \\ ${ }^{2}$ Department of Electronics and Communication Engineering, Sri Venkateswara Engineering College, \\ Karakambadi Road, Tirupati, Andhra Pradesh 517507, India \\ ${ }^{3}$ Department of Science and Humanities, Sri Venkateswara College of Engineering, Karakambadi Road, \\ Tirupati, Andhra Pradesh 517507, India \\ ${ }^{4}$ Center for Applied Sciences, Sree Vidyanikethan Engineering College, A. Rangampet, Tirupati, 517502, \\ Andhra Pradesh, India \\ ${ }^{5}$ Department of Chemistry, S. V. University, Tirupati-517501, Andhra Pradesh, India
}

(Received April 08, 2021; Revised June 22, 2021; Accepted July 16, 2021)

\begin{abstract}
The porous poly(2-naphthol) was made-up by combining the 2-naphthol, dimethoxymethane as an cross linker in presence of $\mathrm{FeCl}_{3}$. Furthermore the polymer was functionalized with $\mathrm{ClSO}_{3} \mathrm{H}$ to get a dense acid catalyst. The reagent is active for benzylation of arenes with benzylic alcohols irrespective of the nature of substituted arenes. This catalyst is good active compared with other acid catalyst used for Friedel-Crafts benzylation.
\end{abstract}

Keywords: Heterogeneous acid catalysis; Friedel-Craft benzylation; green chemical method; recyclability. (C)2021 ACG Publication. All right reserved.

\section{Introduction}

The use of heterogeneous acid catalysts for Friedel-Crafts reaction through green and sustainable chemistry has attracted considerable attention, and these are preferred over conventional hazardous and corrosive homogeneous acid catalysts ${ }^{1}$. Additionally unpolluted and recyclability, solid acid catalysts are fairly cheap, large surface area, good thermal stability, and strongly acidic sites. Yet, so far, the best part of acid catalysts reported is expensive or involve complex synthetic procedures and by products were toxic gas. Examples of these catalysts include sulfated zirconium ${ }^{2}$, heteropoly phosphotungstate ${ }^{3}$ fluorinated porous polymer ${ }^{4}$. Compared to recently reported heterogeneous porous acid catalysts such as Zeolite ZSM- $5^{5}$, sulfonated zirconium and iron containing metal-organic-framework (MOF), trimetalic $\mathrm{Fe}(3)-\mathrm{Ce}(8)-\mathrm{Zr}(12)-$ SBA- $15^{6}$, and sulfonic acid functionalized hypercrosslinked porous polymers have been extensively studied for Friedel-Crafts reactions and also the catalyst preparation were took long time and need use costly surfactants ${ }^{7}$. 


\section{Back ground}

The enlargement of functionalized porous polymers (FPPs) offers immense potential in catalyst design for efficient large-scale chemical conversions. FPPs with good surface area receiving important attention in the fields of dye degradation, catalysis, adsorption, chromatography, and sensor technology ${ }^{8,9}$. Owing to the broad importance of FPPs there are various functionalized porous polymers were synthesized by using various chemical modifications, such as amine, ethylenediamine ${ }^{10}$, Tröger's base, 4-(N,Ndimethylamino)pyridine ${ }^{11,12}$ and sulfonic acid ${ }^{13}$. Among these the sulfonic acid functionalised various porous polymers with different monomers used as catalyst were used efficiently for the various conversions such as glucose or fructose to furfural, esterification's and trans esterification's, Friedel-Crafts reaction, bis(indolyl)methanes.

The benzylation of aromatic moieties was undergone through Friedel-Crafts reaction is a key for the formation direct $\mathrm{C}-\mathrm{C}$ bond formation to construct diarylmethanes and their derivatives were potent industrial and pharmaceutical applications. In general Friedel-Crafts reaction takes in between aromatic hydrocarbons and alkyl halides in presence of various Lewis acid catalysts (e.g., $\mathrm{FeCl}_{3} \mathrm{AlCl}_{3}$ and $\mathrm{H}_{2} \mathrm{SO}_{4}$ ) which does not satisfy the current demand for environmentally benign conditions due to the corrosion, pollution, and difficult for the separation of these homogeneous acid catalysts ${ }^{14,15}$. Benzyl alcohol is one of the most eco-friendly benzylation reagents to replace alkyl halides in view of green chemical method. There are various environmentally benign catalyst have been studied in benzylation reaction of benzyl alcohol to solve the problems of mineral acid catalysts. However the reports revealed that the self-condensation of benzyl alcohol is more favorable than benzylation of aromatic ${ }^{16}$. Furthermore, the mono benzylation of aromatic further react with benzyl alcohol to formation of polybenzylated aromatic at high temperature and strong acidity ${ }^{17}$. To prevent for self-condensation and polybenzylated we have used sulfonic acid functionalized poly(2naphthol) porous polymer (p2NPh- $\left.\mathrm{OSO}_{3} \mathrm{H}\right)$ as catalyst (Scheme 1).
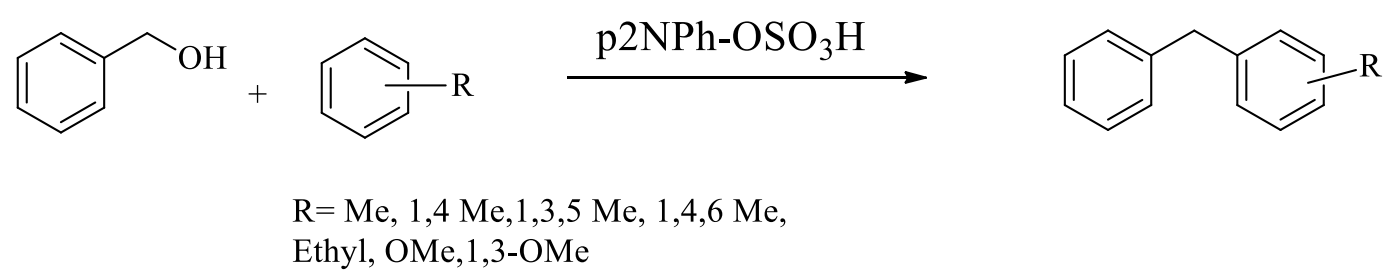

Ethyl, OMe, $1,3-\mathrm{OMe}$

Scheme 1. Benzylation of arenes with benzyl alcohol

\section{Experimental}

\subsection{Chemical and Analysis}

Formaldehyde dimethyl acetal (FDA; 98\%), 2-Naphthol (2NPh-OH) and obtained from local company, chlorosulfonic acid and various aromatic hydrocarbons and benzyl alcohol (BA) obtained from Merck, anhydrous $\mathrm{FeCl}_{3}$ (98\%) from Acros, 1,2-dichloroethane (DCE) from local company, were used as received. The various characterization techniques methods and data was used in our earlier publication ${ }^{18}$. The gas chromatography (GC, Shimadzu GC-2014) equipped with a flame ionization detector and a capillary column $(\mathrm{SE}-30,50 \mathrm{~m} \times 0.25 \mathrm{~mm} \times 0.6 \mathrm{~m})$.

\subsection{General Procedure for Benzylation Reaction}

The benzylation reaction of anisole and benzyl alcohol was performed in a $10 \mathrm{~mL}$ round-bottom flask armed with a reflux condenser and a magnetic stirrer. In a distinctive run, benzyl alcohol (1 $\mathrm{mmol})$, anisole $(2 \mathrm{mmol})$, and catalyst $\left(15 \mathrm{mg}\right.$ ) were placed into the flask. The subsequent mixture was heated at $120{ }^{\circ} \mathrm{C}$ for 4h. After reaction, ethyl acetate was added to the reaction mixture to separate the catalyst and the reaction mixture was concentrated and the standard THF was added and analyzed by a gas chromatography (GC, 
Friedel-Crafts benzylation of arenes with benzylic alcohols

Shimadzu GC-2014) equipped with a flame ionization detector and a capillary column (SE-30, $50 \mathrm{~m} \times 0.25 \mathrm{~mm} \times 0.6 \mathrm{~m})$. The major alkylation product including p-directing and o-directing benzyalted products, were detected there is no by product dibenzylether (DBE) was not identified by GC.

\section{Present Study}

The constructed $\mathrm{p} 2 \mathrm{NPh}-\mathrm{OSO}_{3} \mathrm{H}$ is fully characterized by IR, XRD, SEM, TGA, BET and XPS the obtained data is identical with our earlier reported work ${ }^{16}$. From sustainable chemistry point of view, alkylation's utilizing alcohols are valuable since the only reaction by-product is water. Friedel-Crafts (FC) benzylation is one of the basic approaches for the synthesis of various diary alkanes, which are essential intermediates in pharmaceuticals, cosmetics, dyes, petrochemicals, and numerous chemical manufacturing companies. The benzylation reactions are generally synthesized by using homogeneous acid catalysts such as $\mathrm{AlCl}_{3}, \mathrm{FeCl}_{3}, \mathrm{ZnCl}_{2}, \mathrm{HF}, \mathrm{BF}_{3}, \mathrm{H}_{2} \mathrm{SO}_{4}$ and with alkyl halides as alkylating agents ${ }^{17}$. However, these catalysts have some problems such as high toxicity, corrosion, handling, and difficulty in separating and recovery of the catalyst. To solve this problem the researchers have been developed various heterogeneous acid catalyst with Ecofriendly nature for alkylation of hydrocarbons ${ }^{5,18,19}$.

With the aim of highly efficient $\mathrm{p} 2 \mathrm{NPh}-\mathrm{OSO}_{3} \mathrm{H}$ as a catalyst for the acylation of various functional group, owing to this we have apply the same catalyst for the benzylation of aromatic hydrocarbons with benzyl alcohols using $\mathrm{p} 2 \mathrm{NPh}-\mathrm{OSO}_{3} \mathrm{H}$ as recyclable catalyst (Scheme 1). To the best of our knowledge, there is no report on the benzylation of aromatic hydrocarbons with benzyl alcohols under sulfonic acid functionalized hypercrosslinked poly2-napthol catalyst. To optimize the reaction conditions a mixture of benzyl alcohol $(4 \mathrm{mmol})$ and anisole $(20 \mathrm{mmol})$ was allowed to react in the presence of 25 and $15 \mathrm{mg}$ of $\mathrm{p} 2 \mathrm{NPh}-\mathrm{OSO}_{3} \mathrm{H}$ for $4 \mathrm{~h}$, under solvent free conditions at $120^{\circ} \mathrm{C}$ (Table 1). Whereas the ratio between benzyl alcohol $(1 \mathrm{mmol})$ and mesitylene $(2 \mathrm{mmol})$ was allowed to react under same condition the conversion is similar with Table 1 entry 2 and 3. It was seen that the optimum amount of the catalyst and ration between benzyl alcohol and anisole is $15 \mathrm{mg}$ and $1: 2$. When $25 \mathrm{mg}$ of catalyst was used, the obtained results did not show any noticeable differences with respect to the conversion and reaction time. Hence we have used 15 $\mathrm{mg}$ of the catalyst for all the reactions to convert alkyl benzenes with 6 hydrocarbons which are available in our list.

Table 1. Optimization of the reaction condition

\begin{tabular}{|c|c|c|c|c|c|c|c|c|}
\hline \multirow{2}{*}{ Entry } & \multirow{2}{*}{ Substrate } & \multirow{2}{*}{$\begin{array}{l}\text { Benzyl } \\
\text { alcohol }\end{array}$} & \multirow{2}{*}{$\begin{array}{c}\text { Catalyst } \\
\text { amount } \\
(\mathrm{mg})\end{array}$} & \multicolumn{3}{|c|}{ Selectivity of Product } & \multirow{2}{*}{ DBE } & \multirow{2}{*}{$\begin{array}{l}\text { Reaction } \\
\text { time (h) }\end{array}$} \\
\hline & & & & $\begin{array}{l}\text { Mono } \\
\text { benzylation }\end{array}$ & ortho & para & & \\
\hline 1 & $\begin{array}{c}\text { Anisole } \\
(20 \mathrm{mmol})\end{array}$ & $4(\mathrm{mmol})$ & 25 & 100 & 19.16 & 80.84 & 0 & 4 \\
\hline 2 & $\begin{array}{l}\text { Anisole } \\
(20 \mathrm{mmol})\end{array}$ & $4(\mathrm{mmol})$ & 15 & 100 & 19.16 & 80.84 & 0 & 4 \\
\hline 3 & $\begin{array}{l}\text { Anisole } \\
(2 \mathrm{mmol})\end{array}$ & 1 (mmol) & 15 & 100 & 19.16 & 80.84 & 0 & 4 \\
\hline
\end{tabular}

To study the scope and limitations of this procedure, various hydrocarbons with one, two and three substitutions were reacted with benzyl alcohol, to the optimized reaction conditions, and the results are presented in Table 2. Most of the hydrocarbons with one, two and three substitutions were reacted with benzyl alcohol. The reaction of p-xylene with benzyl alcohols produce only one product of the corresponding diaryl methane but the reaction of anisole, ethylbenzene, toluene, and 1,3-dimethoxybenzene with benzyl alcohols afford the mixture of two products. 
Kalla et al., Org. Commun. (2021) 14:3 300-304

Table 2. Benzylation of arenes with benzyl alcohol in presence of $\mathrm{p} 2 \mathrm{NPh}-\mathrm{OSO}_{3} \mathrm{H}^{\mathrm{a}}$

\begin{tabular}{|c|c|c|c|c|c|c|}
\hline \multirow{2}{*}{ Entry } & \multirow{2}{*}{ Substrate } & \multirow{2}{*}{$\begin{array}{c}\text { Conversion } \\
\text { of BA\% }\end{array}$} & \multicolumn{3}{|c|}{ Selectivity of Product } & \multirow{2}{*}{ DBE } \\
\hline & & & Monobenzyaltion & Ortho & Para & \\
\hline 1 & Anisole & 100 & 100 & 19.16 & 80.84 & 0 \\
\hline 2 & Ethylbenzene & 100 & 100 & 40.58 & 59.42 & 0 \\
\hline 3 & Mesitylene & 100 & 100 & & & 0 \\
\hline 4 & Toluene & 100 & 100 & 47.34 & 52.66 & 0 \\
\hline 5 & P-Xylene & 100 & 99.72 & - & - & 0 \\
\hline 6 & 1,3-Dimethoxybenzene & 100 & 100 & 26.45 & 73.55 & 0 \\
\hline
\end{tabular}

The benefits of $\mathrm{p} 2 \mathrm{NPh}-\mathrm{OSO}_{3} \mathrm{H}$ were equated with those of other reported heterogeneous and homogeneous catalysts for the benzylation of arenes, and the results are signified in Table 3. In 2017, Recently Radhika et al. [5] reported the synthesis of benzylation of arenes with benzyl alcohol by using zeolite ZSM-5, wherein this method temperature is high and DBE is also forming with small quantity compared with $\mathrm{p} 2 \mathrm{NPh}-\mathrm{OSO}_{3} \mathrm{H}$. Wang et al. [7] have been reported the use of HDS and HBS sulfonated hypercrosslinked porous polymer acid catalyst for the construction of benzylation of arenes. This method count on the use of HDS is producing nearly $50 \%$ DBE. Xie et al. [20] reported using brønsted-lewis acidic heteropoly phosphotungstates as a catalyst for the synthesis of benzylation of arenes, in this some of the heteropoly phosphotungstates giving DBE with good yields than that of Ortho and Para directing products. Compared to the above-mentioned catalysts, the p2 $\mathrm{NPh}-\mathrm{OSO}_{3} \mathrm{H}$ termed herein is greater for giving only ortho and para directing products there is no formation of DBE.

Table 3. Comparison of various catalysts used for the benzylation of arenes

\begin{tabular}{ccccc}
\hline Entry & Catalyst (mg) & Time (h) & DBE & Ref. \\
\hline 1 & zeolite ZSM-5 (250) & 1 & 2.4 & 5 \\
2 & $\mathrm{HDS}$ and HBS (100) & 4 & 48.1 & 7 \\
3 & $\mathrm{NH}_{2} \mathrm{SO}_{3} \mathrm{H}(200)$ & 2 & 74.1 & 20 \\
4 & $\mathrm{p} 2 \mathrm{NPh}-\mathrm{OSO}_{3} \mathrm{H}(15)$ & 4 & 0 & This work \\
\hline
\end{tabular}

In conclusion the catalyst displayed good activities for the benzylation of arenes with benzyl alcohol. The catalyst also showed only ortho and para benzylation there is no polybenzylation and di benzyl ether formation.

\section{Acknowledgements}

The authors are grateful to the management and principals of SV Colleges for their support and encouragement during the research.

\section{ORCID}

Reddi Mohan Naidu Kalla:0000-0001-7689-2242

Raju Chakali: 0000-0002-9766-5046

Muni Krishna Amudala: 0000-0002-5815-2707

Mavallur Varalakshmi: 0000-0001-6638-6813

Chamarthi Naga Raju: 0000-0001-6566-2118 
Friedel-Crafts benzylation of arenes with benzylic alcohols

\section{References}

[1] Schriesheim, A. In Friedel-Crafts and Related Reactions; G. A. Olah, Ed.; John Wiley and Sons; New York, 1965; Vol. II.

[2] Zhichao, M.; Jin, Z.; Jinping, Z.; Dandan, L.; Xu, B.; Lingjun C.; Shuping, Z. A novel mesoporous sulfated zirconium solid acid catalyst for Friedel-Crafts benzylation reaction. Appl. Surf. Sci, 2017, 411, 419-430.

[3] Bing, Y.; Yinglian, L.; Zhilie, W.; Fengali, Y.; Congxia and X.; Shitao, Y. A novel Brønsted-Lewis acidic catalyst based on heteropoly phosphotungstates: Synthesis and catalysis in benzylation of p-xylene with benzyl alcohol. Mol. Catal. 2017, 443, 110-116.

[4] Qi, S.; Kewei, H.; Kunyue, L.; Xianfeng, Y.; Briana, A.; Yinyong, S.; Anmin, Z.; Xiangju, M.; Shengqian, M.; Feng-Shou, X. A porous Brønsted superacid as an efficient and durable solid catalyst. J. Mater. Chem. A 2018, 6, 18712-18719.

[5] Radhika, N. P.; Rosilda, S.; Rita, K.; Hsiu-Ling, H. Nanocrystals of zeolite ZSM-5 as catalysts for the liquid phase benzylation of anisole with benzyl alcohol. J. Nanosci. Nanotechnol. 2017, 17, 1329-1337.

[6] Bahrami, K.; Khodaei, M. M.; Fattahpour, P.; Shahrokh, S. Preparation of trimetallic $\operatorname{Fe}(3)-\operatorname{Ce}(8)-\operatorname{Zr}(12)-$ SBA-15 and its application in benzylation of arenes. J. Porous Mater. 2016, 23, 47-55.

[7] Wang, Z.; Niu, G.; Chen, X. Polymeric materials for theranostic applications. Pharm. Res. 2014, 31, 13581376.

[8] Dawson, R.; Laybourn, A.; Khimyak, Y.Z.; Adams, D.J.; Cooper, A.I. High surface area conjugated microporous polymers: the importance of reaction solvent choice. Macromolecules 2010, 43, 8524-8530.

[9] Maly, K.E. Assembly of nanoporous organic materials from molecular building blocks. J. Mater. Chem. 2009, 19, 1781-1787.

[10] Kalla, R.M.N.; Varyambath, A.; Kim, M.R.; Kim, I. Amine-functionalized hyper-crosslinked polyphenanthrene as a metal-free catalyst for the synthesis of 2-amino-tetrahydro-4H-chromene and pyran derivatives. Appl. Catal. A 2017, 538, 9-18.

[11] Du, X.; Sun, Y.; Tan, B.; Teng, Q.; Yao, X.; Su, C.; Wang, W. Tröger's base-functionalised organic nanoporous polymer for heterogeneous catalysis. Chem. Commun. 2010, 46, 970-972.

[12] Zhang, Y.; Zhang, Y.; Sun, Y.L.; Du, X.; Shi, J.Y.; Wang, D.; Wang, W. 4-(N,N-dimethylamino)pyridineembedded nanoporous conjugated polymer as a highly active heterogeneous organocatalyst. Chem. Eur. J. 2012, 18, 6328-6334.

[13] Kalla, R. M. N.; Kim, M.-R.; Kim, I. Sulfonic acid-functionalized, hyper-cross-linked porous polyphenols as recyclable solid acid catalysts for esterification and transesterification reactions. Ind. Eng. Chem. Res. 2018, 57, 11583-11591.

[14] Li, K.; Chen, L.; Wang, H.; Lin, W.; Yan, Z. Heteropolyacid salts as self-separation and recyclable catalysts for transesterification of trimethylolpropane. Appl. Catal. A 2011, 392, 233-237.

[15] Ma, B.; Zhao, W.; Zhang, F.; Zhang, Y.; Wu, S.; Ding, Y. A new halide-free efficient reaction-controlled phase-transfer catalyst based on silicotungstate of $\left[\left(\mathrm{C}_{18} \mathrm{H}_{37}\right)_{2}\left(\mathrm{CH}_{3}\right)_{2} \mathrm{~N}\right]_{3}\left[\mathrm{SiO}_{4} \mathrm{H}\left(\mathrm{WO}_{5}\right)_{3}\right]$ for olefin epoxidation, oxidation of sulfides and alcohols with hydrogen peroxide. RSC Adv. 2014, 4, 32054-32062.

[16] Kalla, R.M.N.; Reddy, S.S.; Kim, I. Acylation of phenols, alcohols, thiols, amines and aldehydes using sulfonic acid functionalized hyper-cross-linked poly(2-naphthol) as a solid acid catalyst. Catal. Lett. 2019, 149, 26962705.

[17] Friedel, C.; Crafts, J.M. The friedel-crafts alkylation and acylation reactions. Compt. Rend. 1877, 84, 49-52

[18] Sun, Q.; Hu, K.; Leng, K.; Yi, X.; Aguila, B.; Sun, Y.; Zheng, A.; Meng, X.; Ma, S.; Xiao, F.S. J. Mater. Chem. A 2018, 6, 18712-18719.

[19] Li, J.; Wang, X.; Chen, G.; Li, D.; Zhou, Y.; Yang, X.; Wang, Hypercrosslinked organic polymer based carbonaceous catalytic materials: Sulfonic acid functionality and nano-confinement effect. Appl. Catal. B. 2015, 176-177, 718-730.

[20] Yuan, B.; Li, Y.; Wang, Z.; Yu, F.; Xie, C.; Yu, S. A Novel Brønsted-Lewis acidic catalyst based on heteropoly phosphotungstates: Synthesis and catalysis in benzylation of $p$-xylene with benzyl alcohol. Mol. Catal. 2017, $443,110-116$.

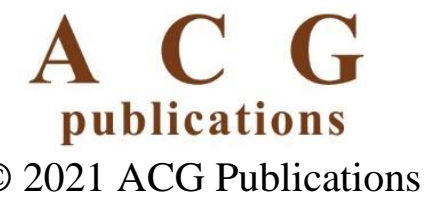

